\title{
ENTRE CORPOS E INTERDIÇÕES: DISCUTINDO SEXUALIDADES DOS SUJEITOS COM DEFICIÊNCIA FÍSICA E/ OU COGNITIVA
}

\author{
BETWEEN BODIES AND INTERDITIONS: DISCUSSING \\ SEXUALITIES OF SUBJECTS WITH PHYSICAL AND / OR \\ COGNITIVE DISABILITY
}

DOI: http://dx.doi.org/10.5965/1984317816012020171

\author{
Rodrigo Lemos Soares \\ Universidade Federal de Pelotas \\ guidodanca@hotmail.com
}

Ariana Souza Cavalheiro

Universidade Federal do Rio Grande coordenadora.arianacavalheiro@gmail.com

\begin{abstract}
RESUMO
As sexualidades, em específico, as de pessoas com as ditas deficiência física e/ ou cognitiva é o centro deste texto. Isso, porque, compreendemos que a sexualidade, como mais uma produção sócio-histórica-cultural, precisa ser debatida reiteradas vezes, nos diferentes campos educacionais. O presente artigo, por sua vez, se destina a discutir sobre noções de sexualidade narradas por sujeitos responsáveis por pessoas com deficiência física e/ ou cognitiva. Nosso aporte metodológico é o campo dos Estudos Culturais, na sua vertente pós-estruturalista e as ferramentas para produção de dados foram um grupo focal e entrevistas semiestruturadas. Os materiais produzidos foram debatidos, a partir da técnica denominada Análise de Conteúdo. Segundo as análises dos materiais percebemos que a sexualidade dos sujeitos com deficiência física e/ ou cognitiva, para além de silenciada é invisibilizada e quando discutida aparece de forma infantilizada sempre vigiada, seja por professores(as) e responsáveis, na tentativa de reprimir as manifestações de desejos que os sujeitos venham a apresentar, principalmente nos ambientes coletivos.
\end{abstract}

Palavras-chave: Corpos; Sexualidades; Sujeitos com deficiência; Relações sociais; Narrativas.

\begin{abstract}
Specifically, sexualities of people with such physical and / or cognitive impairment is the focus of this text. This, because, we understand that sexuality, as a socio-historical-cultural production, needs to be debated repeatedly in the different educational fields. This article, in turn, is intended to discuss notions of sexuality narrated by subjects responsible for people with physical and / or cognitive disabilities. Our methodological contribution is the field of Cultural Studies, in its poststructuralist aspect and the tools for data production were a focus group and semi-structured interviews. The materials produced were debated, using the technique called Content Analysis. According to the analysis of the materials, we perceive that the sexuality of the subjects with physical and / or cognitive deficiency, besides being silenced, is invisibilized and when discussed appears infantilized form always watched, either by teachers and responsible ones, in the attempt to repress manifestations of desires that the subjects will present, mainly in the collective environments.
\end{abstract}

Keywords: Bodies; Sexualities; Subjects with disabilities; Social relationships; Narratives. 


\section{INTRODUÇÃO}

Este trabalho tem o objetivo de discutir sobre as sexualidades de sujeitos com diferentes necessidades físicas e/ ou cognitivas, de modo a serem atendidos por um local de ensino voltado para este público. Especificamente, trataremos das formas e modos, como as(os) responsáveis por estas pessoas narram os corpos e sexualidades destes sujeitos, considerando as formas de ver e viver o mundo das sexualidades, a partir das interações sociais. O nosso estudo abrange sujeitos com diferentes especificidades, dentre elas as cognitivas, mentais e/ou físicas. Iniciaremos com a problemática sobre o conceito de sexualidade, expomos a metodologia e apresentamos as categorias de análise do que foi concebido com relação às narrativas dos sujeitos em um grupo focal.

Percebemos que a sexualidade assume um papel social para além das concepções Bio-reprodutivas. Compreendemos, então que se trata um constructo social, onde nós sujeitos sofremos constantes atravessamentos sobre suas sucessivas manifestações, cada vez menos veladas se comparadas com algumas concepções de Séculos passados. Isso sem negligenciarmos o fato de que a sexualidade é construída por toda a nossa vida, ela não cessa de ser produzida e modificada (LOURO, 2007). Para tanto, entendemos a sexualidade a partir do referencial Foucaultiano, no qual, a sexualidade é um dispositivo1. Segundo Michel Foucault (1988),

[...] não se deve descrever a sexualidade como um ímpeto rebelde estranho por natureza e indócil por necessidade, a um poder que, por sua vez, esgota-se na tentativa de sujeitá-la e muitas vezes fracassa em dominá-la inteiramente. Ela aparece mais como um ponto de passagem particularmente denso pelas relações de poder; entre homens e mulheres, entre jovens e velhos, entre pais e filhos, entre educadores e alunos, entre padres e leigos, entre administração e população (FOUCAULT, 1988, p.67).

\footnotetext{
1 Segundo o Vocabulário de Michel Foucault: 1) O dispositivo é a rede de relações que podem ser estabelecidas entre elementos heterogêneos: discursos, instituições, arquiteturas, regramentos, leis, medidas administrativas, enunciados científicos, proposições filosóficas, morais, filantrópicas, o dito e o não dito. 2) 0 dispositivo estabelece a natureza do nexo que pode existir entre esses elementos heterogêneos. Por exemplo, o discurso pode aparecer como programa de instituição, como um elemento que pode justificar ou ocultar uma prática, ou funcionar como uma interpretação a posteriori dessa prática, oferece-lhe um campo novo de racionalidade (CASTRO, 2009. p, 124).
} 
Entendemos a partir de Foucault que suas produções não se prenderam ao registro das manifestações sexuais através das épocas e civilizações, mas que produz uma história de como a nossa sociedade por muito tempo conectou o sexo a noção de verdade através de análises de mecanismos de poder. A sexualidade é uma elaboração social que opera dentro dos campos do poder, e não simplesmente dentro dos estímulos biológicos que encontram ou não uma liberação direta (GUIDDENS, 1993). Desse modo, ela é passível de ser reorganizada, reinventada, voltando-se a uma pluralidade de possibilidades potencializando as vertentes de verdade sobre os corpos (LOURO, 2007).

Neste viés, apresentamos o sexo como um mecanismo de desejo (BUTLER, 2000) entre os sujeitos com deficiência, sejam elas mentais e/ ou físicas, por entender que estas são necessidades fisiológicas inerentes a todas(os) as(os) humanas(os). Nossa intenção é então discutir ao longo da escrita sobre sexualidade, abordando as possibilidades e as considerações de pensarmos sobre sujeitos com deficiência expondo através de narrativas de seus responsáveis, interdições impostas aos corpos destes(as), que são mantidos sob a guarda e vigilância de diferentes sujeitos e atores sociais, dos locais onde circulam. Isso porque, compreendemos que estes sujeitos, como todo ser humano, primeiro vivência os papeis de gênero e sexualidade, para depois, propriamente, experimentar o sexo (BUTLER, 2000).

\section{CAMINHOS METODOLÓGICOS...}

Para produzir essa pesquisa nos apoiamos nos Estudos Culturais (EC), que, segundo Escosteguy (2006) é o "[...] movimento mais recente onde autores contemporâneos almejam uma conexão mais forte entre estudos culturais centrados mais numa análise teórica e de crítica cultural - e intervenção política" (ESCOSTEGUY, 2006, p. 04). Essa perspectiva teórica vem mostrando que há uma gama de culturas e essas precisam ser investigadas, considerando fundamentalmente as suas particularidades. Os EC estão comprometidos com análises relacionadas às artes, às crenças, aos discursos contidos nos diferentes tipos de linguagem que perpassam a sociedade, privilegiando aquelas 
manifestações culturais que vão de encontro com as concepções tradicionais da cultura. Para Stuart Hall (1996), "[...] os EC se constituíram como um projeto político de oposição, e suas movimentações sempre foram acompanhadas de transtorno, discussão, ansiedades instáveis" (HALL, 1996, p. 263).

Além disso, os Estudos Culturais permitem pensar na relação entre poder e cultura. De acordo com Giroux (2005), essa perspectiva teórica abarca "[...] uma grande diversidade de fenômenos culturais e sociais que caracterizam um mundo pós-industrial cada vez mais hibridizado". Isto é, sua escolha da prática é pragmática, estratégica e autorreflexiva (GIROUX, 2005, p.90). Ainda, Carvalho (2012) afirma que:

[...] os EC não possuem uma metodologia própria, mas sim uma grande flexibilidade na absorção de outras metodologias em princípio, a flexibilidade parece ser uma aliada na construção da metodologia, mas rapidamente ela se transforma em um problema a ser resolvido. $\mathrm{O}$ fato de possibilitar o uso de metodologia variada (e até mesmo a combinação de diferentes opções metodológicas) pode transformar a pesquisa em um Frankstein mal acabado (CARVALHO, 2012, p.3).

Marcamos um grupo focal na Universidade Federal do Rio Grande, no prédio 2 , no dia, 13/03/2018 às 14 horas, horário que ficou melhor aos participantes. A partir das discussões relacionadas à sexualidade delineamos as questões que pareciam mais pertinentes à pesquisa, deixando para reiterá-las no Grupo Focal, do trabalho, pois entendemos que só vivenciando aquele contexto teríamos alguma base para preparar os questionamentos e analisar as narrativas dos entrevistados.

A ferramenta que utilizamos para a produção das narrativas para esse trabalho foi o Grupo Focal, bastante usado em pesquisas qualitativas que preveem a obtenção das informações, a partir de discussões em grupo, nas quais os indivíduos podem expressar "[...] suas percepções, crenças, hábitos, valores, restrições, preconceitos, linguagens e simbologia, permitindo compreender os processos de construção da realidade por determinados grupos sociais" (GATTI, 2005, p.11), através da interação entre os sujeitos. Optamos por esta técnica devido a gama de possibilidades que ela confere, seguindo por uma ideia de possíveis múltiplos olhares sobre a mesma temática, bem como a entender os fatores que definem as 
opções, os porquês de determinados posicionamentos. O Grupo Focal pode possibilitar que as experiências cotidianas e o contexto em que os sujeitos estão inseridos sejam dados relevantes, compartilhando do que afirma Moraes (1999). Dessa maneira, o Grupo Focal permitiu-nos perceber, através das conversas, qual/ quais a(s) concepção(ões) e sentimentos do grupo, em questão, pais e mães, responsáveis legais por sujeitos com deficiências.

Além disso, o Grupo Focal é indicado para pesquisas sociais e humanas, pois, conforme Gatti (2005) possibilita diversos pontos de vista sobre o mesmo tema, através da interação, criada entre as participantes, aspecto primordial para obtenção das informações, permitindo a captação de significados que talvez não aparecessem em outros meios, priorizando, dessa forma, as experiências pessoais que surgem durante as discussões em grupo. Por isso, esse instrumento possibilitou a esta investigação uma produção de informações qualitativas de maneira rápida, com baixo custo e de extrema relevância para este trabalho. Entendemos que quanto mais próximos dos sujeitos maiores foram os espaços que conseguimos para que as narrativas ocorressem e, assim, formamos mais laços, que foram importantes à pesquisa seguindo as orientações de Moraes (1999), ao afirmar que "[...] para entender os significados de um texto é preciso levar o contexto em consideração" (MORAES, 1999, p. 04).

Em relação à análise das narrativas, optamos por trabalhar com 0 procedimento denominado Análise de Conteúdo (AC), a partir de Moraes (1999), quando define esta como "[...] uma metodologia de pesquisa usada para descrever e interpretar o conteúdo de toda classe de documentos e textos" (MORAES, 1999, p. 19). Este autor, ainda, salienta que a utilização dessa técnica, "[...] conduz a descrições sistemáticas, qualitativas ou quantitativas, ajudando a reinterpretar as mensagens e a atingir uma compreensão de seus significados num nível que vai além de uma leitura comum" (MORAES, 1999, p.19).

No entanto, quando se utiliza a análise de conteúdo, uma clara explicitação de objetivos ajuda a delimitar os dados efetivamente significativos para uma determinada pesquisa. Temos inúmeras formas de definir possíveis objetivos de pesquisas realizadas, utilizando análise de conteúdo. Entretanto, o autor recomenda 
que a definição considere seis conjuntos investigativos, que levam em conta os aspectos intrínsecos desta análise, do contexto a que as pesquisas se referem e das inferências pretendidas. Esta classificação se baseia numa definição original de Laswell (MORAES, 1999), quando este orienta que o processo investigativo parta de seis questões: 1) Quem fala? 2) Para dizer o que? 3) A quem? 4) De que modo? 5) Com que finalidade? 6) Com que resultados? Moraes (1999) afirma que, utilizando esta definição, podemos categorizar os objetivos da análise de conteúdo de acordo com a orientação que toma em relação a estas seis questões. Direcionando-nos às leituras das narrativas, ressaltamos esse autor ao escrever que, de certo modo, "[...] a análise de conteúdo é uma interpretação pessoal por parte do pesquisador com relação à percepção que tem dos dados. Não é possível uma leitura neutra" (MORAES, 1999, p. 03). Quanto à busca de material, fontes, utilização e manuseio desta técnica Moraes (1999), afirma que:

A matéria-prima da análise de conteúdo pode constituir-se de qualquer material oriundo de comunicação verbal ou não verbal, como cartas, cartazes, jornais, revistas, informes, livros, relatos autobiográficos, discos, gravações, entrevistas, diários pessoais, filmes, fotografias, vídeos, etc. Contudo os dados advindos dessas diversificadas fontes chegam ao investigador em estado bruto, necessitando, então ser processados para, dessa maneira, facilitar o trabalho de compreensão, interpretação e inferência a que aspira a análise de conteúdo (MORAES, 1999, p.03).

Salientamos que a categorização, descrição e interpretação são etapas essenciais desta metodologia de análise. Segundo este mesmo autor, o processo de análise das narrativas divide-se em cinco fases: 1 - Preparação das informações; 2 Unitarização ou transformação do conteúdo em unidades; 3 - Categorização ou classificação das unidades em categorias; 4 - Descrição; 5 - Interpretação. Dessa forma, a partir do recolhimento material, trabalhamos com "[...] um conjunto de técnicas de análise que, através de uma descrição sistemática, qualitativa, possibilita níveis de compreensão mais profundos sobre o assunto que se pretende investigar" (MORAES, 1999, p. 02).

Os sujeitos, que possibilitaram a realização desta investigação, são todos(as) pais e mães de sujeitos com algum tipo de deficiência e do município do Rio Grande (RS). Para esta pesquisa foram entrevistados(as) quatro mães e dois pais, os(as) 
quais se mostraram solícitos(as) a pesquisa no decorrer das visitas de observação e um ambiente comum a todos(as) no qual responderam mais abertamente sobre suas manifestações corporais, intuito do trabalho. As questões do Grupo Focal foram preparadas e ficaram divididas em três subgrupos: $1^{\circ}$ ) Eixo Pessoal, no qual nos interessou a trajetória escolar e a vida dos(as) depoentes; $2^{\circ}$ ) Eixo Social, composto por questões voltadas às visões que tinham dos sujeitos e de si, estruturação dos sujeitos, identidades e $3^{\circ}$ ) Eixo Específico, momento central do trabalho, em que investigamos acerca das sexualidades dos(as) filhos(as) deles(as).

A partir dessas contextualizações e da temática de estudo, justificamos as escolhas pelos EC e AC, pois os mesmos permitiram pensar nas relações entre poder e cultura. Assim, partindo dessa conceituação entendemos que os EC, de certa forma contemplariam nossa pesquisa, por estarmos focados em uma temática que exige antes da coleta de dados um aprofundamento teórico e cultural dos signos que a interpelam. Nossos dados foram produzidos pelas observações, entrevistas semiestruturadas e um grupo focal que foi constituído após as observações seguido de um convite e da apresentação do termo de consentimento livre e explicado contendo as condições de participação e exclusão, bem como exemplificando que somente os dados seriam utilizados sem que os sujeitos fossem expostos e que os mesmos poderiam se retirar a qualquer momento.

\section{SEXUALIDADES... UM PLURAL DE DISCUSSÕES NECESSÁRIAS}

Um tabu que permeia a sociedade, ainda hoje, é falar sobre a Sexualidade Humana (LOURO, 2007). Somos frutos de muitas manifestações culturais um tanto quanto, arraigadas as normas e crenças de comportamentos cristianizados, heterossexuais normativos, que Ihes embasam, principalmente no ocidente. No entanto, este ato faz com que a sexualidade esteja remetida diretamente aos órgãos sexuais e ao próprio ato sexual, não podendo ser muito comentada, pois é "feio, inadequado e vergonhoso", segundo alguns sujeitos de pesquisa. Segundo Giddens (1993): 
cada um de nós tem, ou cultiva, não mais a uma condição natural que o indivíduo aceita como um estado de coisa pré-estabelecido. De algum modo, que tem de ser investigado, a sexualidade funciona como um aspecto maleável do eu, um ponto de conexão primário entre o corpo, a autoidentidade, e as normas sociais (GIDDENS, 1993, p.25).

Entretanto, o crescente número de estudos e discussões que ampliam esse tema embasam-nos e é nessa perspectiva que nos encontramos: no questionamento das normas. Na intenção de abranger e/ou transformar a visões acima citadas buscamos nas bases (instituição formal de ensino e instituição família) as razões que determinaram e ainda determinam os lugares da sexualidade dos sujeitos que orientam este estudo. No dia marcado para uma das conversas com uma especialista ${ }^{2}$ em educação especial, ao esperar a chegada da mesma, escutamos alguns relatos de mães, de modo informal, quando o assunto transcorria sobre sexualidade ${ }^{3}$. Entre os(as) responsáveis os relatos foram os mesmos, o (a) fulano (a) ta namorando? Poderíamos marcar para que eles se aproximem? Tu levas ele lá em casa e nós os deixamos a vontade para se conhecerem mais. Nesse momento, inferimos a intervenção da família, que segundo Sigolo (1994), demarca as mães como agentes de superproteção, fator que é sempre impeditivo de um desenvolvimento melhor de seu filho.

A questão do impedir está vinculada a problematização do campo das proibições e vigilância, que são um rígido sistema de controle dos prazeres desses indivíduos, que por vezes burlam e determinam os tipos de relações que os mesmos devem ter, e que por assim sancionar acaba estimulando a formação dos discursos sobre, despertando a curiosidade e por consequência a necessidade de provar, nesse sentido, utilizamos enquanto noção de vigiar as contribuições de Michel Foucault (2004), quando o autor expressa que a vigilância,

\footnotetext{
2 A proposta inicial era realizar um trabalho de pesquisa para um componente curricular da Pós-graduação. Tendo isso em vista, fomos até uma escola conversar com uma professora que possui especialização em Educação Especial, para que ela nos auxiliasse com a temática e, principalmente, como acessarmos os sujeitos do posterior estudo.

3 O assunto da conversa não era tratado como sexualidade, para as mães (em uma tentativa de negar a existência da mesma, de certo, um encabulamento de falar sobre o assunto na frente de estranhos), mas sim, foi denominado de encontrinho.
} 
[...] permite ao poder disciplinar ser absolutamente indiscreto, pois está em toda parte e sempre alerta, pois em princípio não deixa nenhuma parte às escuras e controla continuamente os mesmos que estão encarregados de controlar; e absolutamente "discreto", pois funciona permanentemente e em grande parte em silêncio (FOUCAULT, 2004, p. 148).

Ainda, para este autor, a vigilância hierárquica se realiza por dois caminhos distintos e a partir da explicitação do olhar sobre aqueles(as) que são observados(as) e "[...] das pequenas técnicas das vigilâncias múltiplas e entrecruzadas, dos olhares que devem ver sem ser vistos" (FOUCAULT, 2004, p. 144). Foucault também localiza a primeira forma de controle na disposição física das tendas em um acampamento militar ou nos quartos e mesas de refeições das escolas. Destacamos que esses saberes foram acionados, a medida em que, fomos tendo mais contato com os(as) depoentes e seus/ suas filhos(as). A vigilâncias ocorriam de muitos modos, inclusive de pais e mães sobre filhos(as) que não são os(as) seus/ suas.

A vigilância, em todas as estruturas institucionais, seja de forma explícita ou implícita, viabiliza a disseminação do poder disciplinar, o que Foucault denomina de microfísica do poder (FOUCAULT, 2004a). Isso, independente de qual seja o estabelecimento de formas e de relações de poder, elas permeiam todos(as) e, estão entre todos(as), não numa ótica dualista, mas sim permeando todo o tecido social, todas as formas de relacionamento entre os seres humanos. Para Foucault "[...] o poder, em si, não é bom ou ruim, em realidade o poder produz; ele produz realidade" (FOUCAULT, 2004b, p. 161). Em síntese ele é produtivo.

É nesse caminho que, em alguns momentos, a escola desenvolve - mantém - e se utiliza de noções descompassadas de sexualidade, acerca do que sabem seus educandos e os conteúdos que se utilizam para referir as sexualidades destes, a negação, por vezes, parece ser o melhor caminho para silenciar as necessidades fisiológicas dos sujeitos, nesse momento as ocorrências também podem ser vistas com pessoas ditas "normais", que frequentam uma instituição regular de ensino. Ocorrências essas que, por vezes, coíbem e ademais a isso, podem deturpar as reais necessidades fisiológico-sexuais dos deficientes, bem como determiná-las sem 
prévio questionamento acerca do que é prazer, quando se pensa na vida sexual dos sujeitos apresentam deficiências. A partir disso relacionamos algumas falas dos(as) responsáveis ao serem questionados(as) sobre como seus/ suas filhos(as) exibem suas sexualidades seja em casa e/ ou nas escolas que frequentam. Segundo eles(as):

"- Meu filho não pensa sobre essas coisas! Ele deve escutar em algum lugar, na tv principalmente, mas ele não pensa nas coisas de sexo. Eu acho neh!" (MÃE A).

"- O meu fala em ser pai, mas sempre tento evitar que ele saiba como são feitos os bebês, porque isso pode gerar outras curiosidades nele!" (MÃE C).

“- Minha filha diz que é mãe das bonecas, mas já vi ela buscando na internet coisas de sexo, tipo como se faz filhos!" (PAI B).

"- Meu filho no começo perguntou porque a coisa (o pênis) ficava assim em pé? Logo respondi que isso acontecia as vezes, mas era só ele ficar quietinho que já iria passar, hoje com 15 anos ele sabe, aprendeu com os colegas que fica assim quando ta com tesão e foi mais difícil pra eu explicar!" (MÃE B).

"- Minha filha é muito curiosa, sempre perguntou porque nossos corpos são, principalmente no banho. Também quer saber quando ficará com o mesmo corpo que nós para ter o bebê dela!" (PAI A).

"-Tenho medo de ter esses assuntos com ela, porque ela vai perguntar mais coisas e alimentar o desejo dela, mas ela mexe no seu corpo, já vi ela desfilando na escola se sentindo muito sensual, como ela diz quando pergunto porque estava desfilando daquele jeito." (MÃE D)

Dessa forma, na contramão dos ideais angelicais atribuídos às pessoas com deficiência, com a visão social de corpo sexual e atividade sexual ao declarar a importância dessas relações para o desenvolvimento global dos sujeitos, bem como um provável avanço no que tende ao convívio social, ultrapassando os limites estabelecidos por alguns estudiosos que tendem a firmar a sexualidade desse público como exibicionismo que o trabalho vem para conferir outra visão acerca das sexualidades dos sujeitos deficientes. Nos relatos, percebemos algumas tentativas de negação dos saberes sobre corpo, sexo e sexualidade. As ocorrências vão desde fugas do assunto, até mesmo, escapes de explicações simples, como por exemplo, sobre a estrutura dos nossos corpos.

Uma tentativa de transpor as barreiras sociais, demarcadas pelo processo histórico de formação cultural, para amenizar as diferenciações e aculturações sobre a sexualidade e o humano. Segundo Giami (2004), “[...] os educadores falam sobre 
as relações entre os sexos, as relações sexuais genitais, a masturbação, a homossexualidade masculina e o mongolismo" (GIAMI, 2004, p. 17), as condutas verbais como substitutivas das condutas sexuais e sua oposição às representações dos pais sobre o assunto, que traduzem como de negação da sexualidade desses sujeitos. Nesse momento questionamos quais seriam as principais questões que incomodavam seus pensamentos acerca das sexualidades dos filhos?

\footnotetext{
“- O que me preocupa é que ele seja abusado!" (MÃE A).

“- Fico com receio de que ela tenha algum tipo de ataque por conta dos remédios!" (PAI A).

"- Creio que minha maior preocupação seja o fato de isso nunca ter ocorrido nos meus pensamentos, tenho que protegê-lo, mas também imagino que ele precise ter relações com outras meninas e ele me cobra porque se fala nisso na escola entre eles!" (MÃE B).

“- Sei que ela precisa disso (sexo), até já me falou que aprendeu com os colegas sobre como é mas acho que ela não saberá fazer, se proteger. E se ela engravidar? (MÃE D).

“- Já ví homens olhando pra ela, porque ela mosaico, tem só um pouco da doença e isso me incomoda muito, hoje em dia ninguém respeita ninguém quando o assunto é essas coisas de sexo. Mas professor, ela já perguntou quando ela vai transar!" (PAI B).

“- Ele vê nas novelas e pergunta, conversa na escola e me conta, quer saber porque eles estão deitados na cama, eu fico muito preocupada, porque ele mostra muito interesse nisso (sexo), mas tenho medo de deixa ele se envolver com meninas, só se for como ele, acho que assim fico mais tranquila!" (MÃE C).
}

A partir dos estudos realizados entendemos que a sexualidade está presente nas práticas escolares (LOURO, 2007). Ela permeia as vivencias das crianças e adolescentes e, mesmo que, de maneira implícita, está presente nas relações que eles estabelecem entre si. Partindo do entendimento de que a sexualidade compreende também as questões de gênero (BUTLER, 2000), ressaltamos que até mesmo nas práticas consideradas simples, como por exemplo, separar as filas entre meninos e meninas, assumir determinados discursos sobre o que é atribuído ao sexo feminino ou masculino, sobre o que é ser homem ou ser mulher, os(as) professores(as) estão trabalhando sexualidade na escola. Porém, muitos profissionais da educação não entendem dessa forma, além de não entenderem a sexualidade como um conceito amplo, que aborda diferentes questões, também acreditam que esse assunto deve ser trabalhado de maneira sistematizada. 
Operamos sobre duas possibilidades a noção de sexualidade. A primeira refere-se à orientação sexual, que segundo Suplicy (1999) é um processo formal e sistematizado que se propõe a preencher lacunas de informação, erradicar tabus e preconceitos e abrir discussão sobre emoções e valores que impedem o uso dos conhecimentos. À orientação sexual pode propiciar uma visão ampliada e diversificada acerca da sexualidade. A segunda foi à educação sexual, que para Suplicy (1999) começa na família, pois ela constitui o primeiro grupo social no qual o indivíduo toma contato com o mundo. O contato cotidiano da criança com os pais, o processo de socialização que se segue, a influência da mídia e dos grupos sociais faz parte da educação sexual. É um processo de vida, que permite ao indivíduo se modificar, e só termina com a morte, dialogando com o que expressa Foucault (1988).

Entendemos que ambas as possibilidades estão imbricados nas instituições de ensino. A educação sexual se dá na medida em que a sexualidade está presente em todas as práticas escolares, visto que, para que isso ocorra, os professores devem refletir sobre as atividades desenvolvidas e problematizá-las com os alunos. Mas, consideramos que ao emergir assuntos mais direcionados, questões que precisam ser abordadas com mais ênfase, cabe ao professor buscar estratégias e materiais para subsidiar um trabalho que precisará ser pensado e preparado para determinado grupo, dessa forma existe também a orientação sexual. Entretanto, queremos evidenciar que não entendemos a orientação sexual como uma disciplina a ser trabalhada isolada das demais e discutir assuntos que não tenham emergido do interesse ou necessidades da comunidade escolar atendida.

Para trabalhar a sexualidade na escola, necessitamos procurar diversos recursos, dentre eles ressaltamos o trabalho com artefatos culturais, entendidos como, peças publicitárias, músicas, videoclipes, charges, revistas, jornais, programas televisivos e radiofônicos, entre outras, que são resultados de processos de construção cultural. Tais artefatos contêm pedagogias culturais que ensinam modos de ser e estar no mundo, construindo e reproduzindo significados sociais, por isso é importante trabalhá-los na escola, visando desmistificar os ensinamentos contidos nos currículos. Para Camargo (1999): 
A escola é uma das instituições encarregadas de transmitir cultura e formas de comportamento aceitas pela sociedade, mas pode também ser um espaço de questionamento desses comportamentos. Atualmente, esfacelada por uma série de motivos, a escola contém espaços de resistência, em que a criatividade e a sensibilidade representam possibilidades de problematização de seu papel (CAMARGO, 1999, p. 43).

É possível utilizar também outros recursos pedagógicos desenvolvidos para trabalhar a educação sexual, esses materiais são lúdicos, criativos e desportivos como, por exemplo, os jogos, a música, o esporte, a pintura, modelagem, que deverão estar de acordo com a idade e ao nível de compreensão dos alunos. Esses materiais são elementos integradores e interativos para trabalhar corpo, crescimento, diferenças sexuais, rivalidades, atrações, entre outros.

Conforme Maia \& Ribeiro (2009) existem algumas questões que precisam serem consideradas pelos professores, como, respeitar a idade dos alunos, as condições de compreensão e nível de desenvolvimento mental, cognitivo e social. Ouvir as necessidades deles, o que querem saber, o que pensam sobre a sua sexualidade, respeitar as diferenças de valores familiares, étnicos e culturais. É preciso também usar uma linguagem acessível e não excessivamente técnica, porém, usar palavras corretas, sem eufemismos e infantilizações (associar as palavras "usuais" com os nomes corretos).

\section{SEXUALIDADES EM JOGO...}

Se atualmente as discussões sobre sexualidade com pessoas ditas normais é vista com certos pudores, falar desse assunto em relação aos com deficiência mental e motora é algo bem mais difícil, pois as barreiras aumentam. A percepção social é distorcida e eles são vistos pela sociedade como seres assexuados, incompletos, sem desejos ou às vezes como hiper-sexuadas(os), selvagens que não conseguem se controlar. Essa compreensão se deve a falta de estudos existentes e de informações acerca da sexualidade, que inclusive ajudariam a percebê-la a partir de uma compreensão mais abrangente. Sobre esses "impulsos" os pais apontam que: 
“- Desde que começamos os tratamentos com ele, o médico sempre nos ensinou a conversar com ele sobre o assunto, para que nada fosse tabu, principalmente entre nós e nós tentamos, mas é complicado, acaba que só respondemos o que ele pergunta!" (MÃE C).

“- Já percebi que ela fica muito tempo sentada na guarda do sofá e acho que já ví até cara de prazer, é complicado assumir isso, mas deve ser natural, néh professor? Ela não é doente por isso? Creio que todos nós temos momentos e locais de descobertas, mas ela não fica se expondo, nem agarrando ninguém!" (PAI B).

Muito dos conceitos, acima citados se devem à concepção estereotipada feita em relação a capacidades consideradas limitadas fisicamente, psicologicamente e socialmente dos portadores de deficiência. Contudo, esses fatores podem ser sim barreiras para o desenvolvimento sexual em termos de relacionamentos mais íntimos com o outro, como fala Gale (1989). Segundo o autor o que pode dificultar o processo são barreiras de locomoção, verbais, de isolamento, depressão, falta de convívio, discriminação, entre outros. Isso significa que mesmo diante dessas dificuldades, esses sujeitos não estão impedidos de vivenciarem e de desenvolverem suas sexualidades. São apenas empecilhos que podem ser superados e que, excluindo-se os físicos, na maioria das vezes foram se constituindo pelo convívio social e as visões que seus familiares e comunidade constroem acerca dele.

Mais próximo das pessoas com deficiência, estão os familiares, que em geral carregam percepções que se encontram no grupo social no qual se inserem. Os pais, principalmente, veem seus filhos de forma infantilizada e dificilmente permitem que se relacionem de maneira amorosa com outras pessoas. Acabam isolando seus filhos por conta da superproteção, o que pode fazê-los ficarem tímidos e com sua sexualidade repreendida (GLAT, 1993). Relacionando os dois autores, as concepções familiares podem se tornar uma forma de impedimento do direito ao relacionamento com o outro e de conhecê-lo intimamente. Há um conjunto de fatores que vai sendo somado e que caracteriza cada ser na sua maneira de viver e de se relacionar consigo mesmo e com os outros. Além disso, Glat (1993) ajuda a desmistificar a visão de que são selvagens e que não possuem censuras.

Levando em consideração que a maioria dos sujeitos com deficiência não possui grande privacidade com relação à sua família e que esta não auxilia nas 
questões relacionadas ao descobrimento do próprio ser, a busca pela identidade sexual fica prejudicada e não se acaba conhecendo bem seu próprio corpo. Quando essa descoberta já foi feita e ocorre repressão contra comportamentos como "[...] masturbar-se, rir maliciosamente, dançar, agarrar, abraçar e beijar" (GLAT, 1993, p. 16) pode gerar regressão de aptidões já adquiridas, sofrimento, isolamento, agressão, etc.

A repressão não é o caminho para viver a sexualidade. Mesmo quando um sujeito com deficiência está com sua energia sexual muito elevada e não tem como liberá-la ou relacionar-se com alguém no momento. Torna-se necessário permitir e incluir em sua rotina outras atividades, como esportes, novos lugares, jogos, leituras, a fim de liberar sua energia acumulada por outros meios.

Quando se pensa no binômio deficiência-sexualidade, parece que se tenta resolver um problema que essa relação traria consigo. Por outro lado, quando se pensa sobre essa mesma questão com pessoas ditas normais, não se encontram grandes problemas, embora existam, pois o que se vê são comportamentos "naturais"/ fisiológicos dos seres humanos e que nos constituem nas relações com os demais. Em vez disso, se considera que as atitudes dos sujeitos com deficiência são inadequadas, não possibilitando a compreensão que estas se desenvolvem e maturam sua sexualidade (puberdade, maturação, prazer) como todas as outras pessoas. Pessoas Síndrome de Down sofrem muito desses mitos: suas necessidades, seus desejos e suas capacidades sexuais não são conhecidos, atendidos ou respeitados. Sobre o tópico, o PAI A, afirma que:

"- A fulana vai para as festa da família e as pessoas ficam falando que ela é linda e sem maldades quanto a ser sensual na hora das danças, mas acho que a minha razão de pai, percebe no final de tudo, que em muitos momentos ela tem noção de que está sendo sensual, de alguma maneira!"

Da mesma forma, "[...] os indivíduos portadores de TID (transtornos invasivos do desenvolvimento) apresentam um desenvolvimento biológico normal da sexualidade" (ALMEIDA, 2008, p. 13). Todavia, seu desenvolvimento psicológico sofre algumas alterações e precisam satisfazer seus impulsos imediatamente, apresentar impulsos sexuais agressivos e rudimentares, com ou nenhuma 
autocrítica, distorcendo a realidade ou não conseguindo fantasiar, etc. Haracopos e pederson, (apud ALMEIDA, 2008). Questionamos sobre as formas que se manifestavam quando muito necessitados, e a MÃE D fala que:

"- Tento estar atenta a tudo, mas tem vezes que não dá e quando vejo alguém me chama, porque ela está com a mão lá em baixo (na vagina) e dando risadas altas, masturbando-se em lugares públicos, acontece, por mais que ensinemos eles nos escapam, às vezes!"

É importante ressaltar que os pesquisadores colocam que nem todos esses comportamentos ocorrem, e que pode haver outros comportamentos e que ainda que seja possível existir pessoas que não apresentam nenhuma alteração mais acentuada. Tudo vai depender do grau do autismo e do meio onde a criança/ o adolescente está inserido.

É outra a situação das pessoas com deficiência física. Enquanto que a visão sobre os mentais é repreensiva, como se eles fossem selvagens, ou precisassem ser infantilizados, com os físicos o que ocorre é preconceito social e a existência de barreiras corporais que as experiências dão conta de superar. Além disso, em geral, deve se levar em conta os sentimentos que os sujeitos vão criando acerca de si mesmos, decorrentes de uma baixa autoestima em virtude das concepções perante as suas limitações físicas que distorcidamente são também atribuídas à sua sexualidade. Sobre o assunto a MÃE B, narrou ao grupo que:

"- Ele sempre sonhou em ser pai e nunca deixei esse sonho morrer nele, porque tenho certeza de que mais dia ou menos dia encontrarão um jeito de auxilia-los nessa questão, já tentei reunir outros pais para falarmos disso, mas todos rejeitam, porque dizem que nesses casos não terão cura a esse ponto (deles poderem ter filhos)!"

Percebemos na narrativa da MÃE B uma esperança de que em algum momento existirá meios que possibilitem a realização do sonho de seu filho. A visão estereotipada que a sociedade conceitua sobre os sujeitos com paraplegias em relação à sexualidade se dá pela delimitação das compreensões sobre ela. Não se trata somente do ato sexual em si, mas conjunto de comportamentos que proporciona prazer ao individuo, pois a sexualidade é um constituinte do ser humano, sofrendo influências socioculturais, psicológicas e genéticas. O sentimento 
de incapacidade é mais evidente nos homens por se sentirem incapazes de tomarem iniciativas, terem força, serem produtivos, transmitir segurança e serem indivíduos potentes ${ }^{4}$, isto estando relacionado às concepções socialmente construídas.

A maioria dos homens com lesão medular consegue ter uma vida sexual ativa podendo chegar ao orgasmo e terem filhos, dependendo da gravidade da lesão: se a parte lesionada ocorrer nas áreas conhecidas como sagradas (S2, S3 e S4) ${ }^{5}$, a possibilidade de um homem ter uma ereção é eliminada, - quanto mais alto na coluna for o nível de lesão, mais normal será o seu desempenho sexual. As mulheres também sofrem alterações menos perceptíveis. Conseguem chegar ao orgasmo, manter relação sexual com coito e podem ter filhos. Isto depende também da gravidade da lesão ou doença ao nível neurológico. As modificações que podem ocorrer no ato sexual são a diminuição ou ausência de lubrificação vaginal e do clitóris; desregulamento ou ausência de menstruação; devido à ausência de sensibilidade, a determinação da hora do parto fica prejudicada e infecção urinaria pode ocorrer com frequência (GLAT, 1992). Nos homens a contagem de espermatozoides pode ser baixa ou nula. Hoje em dia existem tratamentos que buscam diminuir as sequelas sexuais em pessoas com lesão medular.

No caso dos sujeitos com espinha bífida, por ser uma doença congênita e que está intimamente ligada à região do desenvolvimento sexual, os adolescentes têm dificuldade de descobrirem e questionarem a sua sexualidade, pois o desenvolvimento da sua sexualidade é entendido pela sociedade e pela sua família como grotesco e com perversidade, que causa repulsa por acharem que é altamente contagioso. A família nesse contexto é vista como o grande repressor do descobrimento da sexualidade do adolescente por permeá-los de sentimentos de dificuldades e insegurança e de rejeição do próximo. As alterações fisio-biológicas das pessoas com espinha bífida ocorrem na sua maioria nos homens devido às limitações de ereção e ejaculação, a falta ou não de sensibilidade nas regiões

\footnotetext{
4 Potente no sentido de ser satisfatório para a(o) parceira(o), com a(o) qual se relaciona.

5 S2, S3, S4 - São vértebras sacrais envolvidas com as questões de enrijecimento peniano e quando lesadas ocorre o grande risco da impotência sexual, nesses indivíduos.
} 
sexuais. Nas mulheres implica a perda ou não da virgindade, por sentirem vergonha em relação ao cateterismo.

Os sujeitos com deficiência visual não apresentam nenhuma dificuldade no desenvolvimento da sua sexualidade, mas a sociedade e a família o limitam, infantilizando, privando o descobrimento de sua identidade sexual, já que às vezes são vistos também como sujeitos assexuados (ALMEIDA, 2008). São excluídos e privados do compartilhamento de experiências e há dificuldade de entender os conceitos sociais relacionados à sexualidade. Nesse sentido, as famílias têm de disponibilizar um espaço que favoreça o desenvolvimento da sexualidade dos sujeitos cegos. A MÃE $A$, ao relatar experiências com o filho que tem baixa visão e hiperatividade conta-nos que:

“- Chega a ser engraçado, porque algumas pessoas chegam nele cheias de dedos e ele abraça mesmo, um dia ele disse toquei no bumbum dela e deu risada, tivemos uma conversa séria sobre, mas não contivemos a risada (a mãe e o pai), percebemos que aquele era o mecanismo de atuação dele para estas questões!

Para suprir a falta de visão os sujeitos com deficiência visual desenvolveram outros mecanismos para perceber o mundo, através do tato e audição eles desvelam as belezas e imperfeições do que está a sua volta. Em relação ao desenvolvimento sexual, os "cegos" exploram o seu corpo a fim de descobrir sua identidade sexual, extravasando sentimentos e angústias muitas vezes reprimidas (GLAT, 1992). As pessoas com deficiência visual, os cegos e demais características oriundas da visão, possuem possibilidades de experienciar seus corpos independente da relação com a vidência. Enxergar ou não, é algo que evitamos relacionar com a produção de desejos e sensação de prazeres, ainda que o contrário possa ser outra possibilidade de lidar com imaginário e, assim, ser relacionado com atitudes que venham colaborar na construção de sentidos, como a libido.

Os sujeitos com deficiência física além de sofrerem préconceitos advindos e da família e da sociedade, passam pela busca e resgate da identidade pessoal que está ligada à imagem corporal, como o sujeito vê o seu corpo e como ele, seu corpo, é visto pelos outros. Socialmente e culturalmente o corpo é fortemente regido por um 
modelo ideal, excluindo e/ou inferiorizando aqueles que não estão padronizados. Isso influencia na autoestima do indivíduo, dificultando a realização plena do ser humano.

\section{CONSIDERAÇÕES ÀS SEXUALIDADES... CAMINHOS PARA OUTROS DEBATES}

Sexualidade e "deficiência" ainda são conceitos mal interpretados, pouco compreendidos na realidade e carregados de estigmas. Quando se trata da relação entre os dois conceitos, os mitos, preconceitos e equívocos aumentam. Seria necessário que a sociedade em geral, a família e os profissionais da educação, dentre outros, tivessem maiores oportunidades de conhecer os sujeitos dentro de suas potencialidades, suas abstrações, idealizações, porém, compreendendo que do modo como se apresentam, são inteiros, reais, imanentes e carregam em si processos individuais de atualização de suas vontades. Este trabalho elucidou-nos que entre as diferentes possibilidades do indivíduo encontra-se a sexual.

Cada pessoa desenvolve características e concepções que consideramos englobar a sexualidade, nesse caso, consideramos que "[...] pessoas ditas 'excepcionais'6 não são necessariamente excepcionais em seus impulsos e desejos sexuais. Elas têm necessidades normais, experiências normais e emoções humanas normais" (GLAT, 1993, p.66). Isso significa que não podemos reduzir o entendimento da sexualidade ao biológico, sem considerar o psicológico, o emocional, as ideias, os desejos. E com as pessoas com deficiência não é diferente, isso porque, temos que compreender que todos somos seres humanos e que essas são as questões que também nos constituem.

Além disso, se levarmos em consideração os benefícios que a vivência sexual permite aos indivíduos, não haveria tanto preconceito contra os sujeitos com deficiência, visto que através dessas práticas podem aumentar a capacidade de interagir e relacionar-se com outros, a autoestima, o desenvolvimento afetivo, o

6 Embora este termo esteja em desuso, optamos por deixá-lo, a fim de apresentarmos os modos como os estereótipos foram se construindo em torno das pessoas com deficiência. 
amor a si e aos outros e seu bem-estar. É uma questão de sobrevivência e de melhoria da própria vida que não pode ser negada.

Essa negação ainda é muito forte atualmente. Quando não ocorre por meio de repressão, se silencia os desejos, se desconsideram as atitudes e se mata uma parte do ser humano. Isso sim poderia ser considerado uma deficiência pela forma como é impedida e retirada das vidas das pessoas. A luta pela igualdade de qualidade de vida e respeito entre as pessoas não pode deixar de fora um direito essencial à vida, que está em nós e que é uma ponte na relação com os demais. Pensar a sexualidade dos sujeitos com deficiência é cada vez mais urgente para que se desmistifiquem essas questões e não se cometam injustiças que possam vir a comprometer a vida de muitas pessoas. Em vista disso, resta-nos pensar sobre o conceito "deficiência" sob outro aspecto, o da repressão, inibição e negação dos desejos do outro, por um caminho ainda mais desrespeitoso, no que diz respeito à integridade e moral do sujeito com deficiência. Burlar a sexualidade do outro sob a alegação de superproteção e/ ou medo ainda sim, significa violar alguns direitos: o da felicidade, de liberdade e da necessidade de expressão e satisfação.

\section{REFERÊNCIAS:}

ALMEIDA, M. S. R. A Expressão da Sexualidade das Pessoas com Autismo. Pro-fala. 2008.

BUTLER, Judith. Corpos que Pesam: sobre os limites discursivos do "sexo". In:

LOURO, G. L. [Org.]. O Corpo Educado. Pedagogia da Sexualidade. 3 ed. Belo Horizonte: Autêntica, 2000. p. 151-172.

CAMARGO, A. M. F. Sexualidade (s) e infância (s): a sexualidade como um tema transversal. Ana Maria Faccioli de Camargo, Claudia Ribeiro; coordenação Ulisses F. Araújo. - São Paulo: Moderna; Campinas, SP: Editora da Universidade de Campinas, 1999. (Educação em pauta: Temas Transversais).

CARVALHO, A.B.G.P. Blog - Estudos Culturais: Cibercultura. 2012. Pós-Modernidade. Mídias. Textualidade.

CASTRO, E. Vocabulário de Foucault - Um percurso pelos seus temas, conceitos e autores/ Edgard Castro; Tradução Ingrid Mulher Xavier; revisão técnica Alfredo Veiga - Neto e Walter Omar Kohan. - Belo Horizonte; Autêntica. 2009.

ESCOSTEGUY, A. C. Uma introdução aos estudos culturais. Revista FAMECOS. Porto Alegre. 2006. 
FOUCAULT, M. Os recursos para o bom adestramento. In: FOUCAULT, M. Vigiar e punir: nascimento da prisão. 29a ed. [Trad.] Raquel Ramalhete. Petrópolis, Rio de Janeiro: Vozes, 2004a, pp. 153 - 172.

$\overline{2004 b}$

Uma entrevista: sexo, poder e a política de identidade. Verve, $n^{\circ} .5$, pp. $260-277$,

História da sexualidade I. A vontade de saber. 10. ed. Rio de Janeiro: Graal, 1988.

Vigiar e Punir: nascimento da prisão. 25.ed. Petrópolis: Vozes, 2004.

GALE, J. O adolescente e o sexo - um guia para os pais. São Paulo: Best Seller. In: MAIA, A.C.B.; CAMOSSA, D.A. Relatos de jovens deficientes mentais sobre a sexualidade através de diferentes estratégias. Universidade Estadual Paulista - Bauru. 1989.

GATTI, B. A. Grupo Focal na Pesquisa em Ciências Sociais e Humanas. Brasília: Líber Livro, 2005.

GIAMI, A., D' ALLONES, C.R. O anjo e a fera: as representações da sexualidade dos deficientes mentais pelos pais e educadores. In: NETTO, M.I.D. (Ed) A negação da deficiência: a instituição da diversidade. Rio de Janeiro: Achiamé/Socius, 2004.

GIROUX, H.A. Praticando Estudos Culturais nas faculdades de educação, In. SILVA, Tomaz Tadeu. Alienígenas na sala de aula: uma introdução aos estudos culturais em educação. Petrópolis: vozes, 2005.

GLAT, R. (1992). A sexualidade da pessoa com deficiência mental. Revista Brasileira de Educação Especial 7(1), 65-74. Paidéia, 2003,12(24), 205-214. In: MAIA, A.C.B.; CAMOSSA, D.A. Relatos de jovens deficientes mentais sobre a sexualidade através de diferentes estratégias. Universidade Estadual Paulista - Bauru.

Somos iguais a vocês: depoimentos de mulheres com deficiência mental. Rio de Janeiro: Agir, 1993. In: LUIZ, E. C.; KUBO, O. M. Percepções de jovens com síndrome de down sobre relacionar-se amorosamente. Rev. Bras. Ed. Esp., Marília, Mai.-Ago. 2007, v.13, n.2, p.219-238.

GUIDDENS, A. A transformação da intimidade: sexualidade, amor e erotismo nas sociedades modernas/ Anthony Guiddens; tradução de Maguida Lopes. - São Paulo: Editora da Universidade Estadual Paulista, 1993 - (Biblioteca Básica).

HALL, S. Estudos culturais e seus legados teóricos. In: MORLEY, David, Kuan-Hsing, C., (eds). Stuart Hall - Diálogos críticos em estudos culturais. London; New York: Routledge. (1996).

LOURO, G. L. [Org.] O corpo educado. Pedagogias da sexualidade. Belo Horizonte: Autêntica, 2007.

MAIA, A. C. B.; RIBEIRO, P. R. M. Orientação sexual e Síndrome de Down: esclarecimentos para educadores. Bauru: Joarte Gráfica e Editora UNESP - F. C, 2009.

MORAES, R. Análise de conteúdo. Revista Educação, Porto Alegre, v. 22, n. 37, p. 7-32, 1999.

SIGOLO, S. R. R. L. Análise da interação mãe-criança com atraso de desenvolvimento no segundo ano de vida. Tese de Doutorado, Universidade de São Paulo, SP.1994. 
SUPLICY, M. Sexo se aprende na escola. Editora: Olho d'água (GTPOS) 2ª ed. 1999.

Recebido em 10/08/2018

Aprovado em 11/11/2019 